\title{
Texture, realism, performance: exploring the intersection of transtexts and the contemporary sitcom
}

Book or Report Section

Published Version

Knox, S. and Derhy Kurtz, B. W. L. (2017) Texture, realism, performance: exploring the intersection of transtexts and the contemporary sitcom. In: Derhy Kurtz, B. W. L. and Bourdaa, M. (eds.) The Rise of Transtexts: Challenges and Opportunities. Routledge Research in Cultural and Media Studies. Routledge, pp. 49-67. ISBN 9781138944671 Available at http://centaur.reading.ac.uk/56220/

It is advisable to refer to the publisher's version if you intend to cite from the work. See Guidance on citing.

Publisher: Routledge

All outputs in CentAUR are protected by Intellectual Property Rights law, including copyright law. Copyright and IPR is retained by the creators or other 
copyright holders. Terms and conditions for use of this material are defined in the End User Agreement.

\section{www.reading.ac.uk/centaur}

\section{CentAUR}

Central Archive at the University of Reading

Reading's research outputs online 


\section{Texture, Realism, Performance: Exploring the Intersection of Transtexts and the Contemporary Sitcom}

(Knox, Simone \& Derhy Kurtz, Benjamin W.L.)

Contemporary US sitcom is at an interesting crossroads: it has received an increasing amount of scholarly attention (e.g. Mills 2009; Butler 2010; Newman and Levine 2012; Vermeulen and Whitfield 2013), which largely understands it as shifting towards the aesthetically and narratively complex. At the same time, in the post-broadcasting era, US networks are particularly struggling for their audience share. With the days of blockbuster successes like Must See TV's Friends (NBC 1994-2004) a distant dream, recent US sitcoms are instead turning towards smaller, engaged audiences. Here, a cult sensibility of intertextual in-jokes, temporal and narrational experimentation (e.g. flashbacks and alternate realities) and selfreflexive performance styles have marked shows including Community (NBC 2009-2015), How I Met Your Mother (CBS 2005-2014), New Girl (Fox 2011-present) and 30 Rock (NBC 2006-2013).

However, not much critical attention has so far been paid to how these developments in textual sensibility in contemporary US sitcom may be influenced by, and influencing, the use of transmedia storytelling practices, an increasingly significant industrial concern and rising scholarly field of enquiry (e.g. Jenkins 2006; Mittell 2015; Richards 2010; Scott 2010; Jenkins, Ford and Green 2013). This chapter will investigate this mutual influence between sitcom and transmedia by taking as its case studies two network shows that encourage invested viewership through their use of transtexts, namely How I Met Your Mother (hereafter HIMHM) and New Girl (hereafter NG). As such, it will pay particular attention to the most 
transtextually visible character/actor from each show: HIMYM's Barney Stinson, played by Neil Patrick Harris, and $N G$ 's Schmidt, played by Max Greenfield.

HIMYM features intratextual elements and has released several books, referenced in the show, as having been written by Barney, while $N G$ features fast-cut sections of improv-style performance and has released in-character videos for its breakout performer Greenfield. This chapter will argue that these shows do not simply have their particular textual sensibility and also (happen to) engage with transmedia practices, but that the two are mutually informing and defining. This chapter will explore the relationships and interplay between sitcom aesthetics, narratives and transmedia storytelling (or industrial transtexts), focusing on the use of multiple delivery channels in order to disperse "integral elements of a fiction" (Jenkins, 2006 95-6), by official entities such as the broadcasting channels. This chapter's conceptual framework will be particularly concerned with how issues of texture, the reality envelope and accepted imaginative realism, as well as performance and the actor's input inform and illuminate contemporary sitcoms and transtexts, and will be the first scholarly research to do so. It will seek out points of connections between two (thus far) separate strands of scholarship and will move discussions on transtexts beyond the usual genre studied (i.e. science-fiction and fantasy), as well as make a contribution to the growing scholarship on contemporary sitcom by approaching it from a new critical angle.

Following the example predominantly set by sci-fi and fantasy programs, situation comedies have recently adopted transmedia strategies. While certain network executives tend to present such extensions as a way to reward fan loyalty (Garron 2006, 198, citing the CBS.com VicePresident), the purpose of such practices is much more pragmatic: they help sustain audience interest, build a comprehensive narrative universe and promote the program in question. Even 
though these extensions are directed to existing - and, more specifically, engaged - audience members, such transtexts can also be used to attract new viewers, by catching their attention on a variety of platforms. This gives them an inherent duality: when seeking to reach longterm and new audiences, transtexts must be sufficiently linked to the source text to both incorporate elements from it and further contribute to it, whilst at the same time be independent enough to work as a standalone piece, understandable on its own, without requiring familiarity with previous extensions (source text included).

Such practices, however, especially in relation to our topic of interest, sitcoms, are fairly new, and were literally non-existent at the time of series like Friends (NBC 1994-2004), Frasier (NBC 1993-2004) or Malcolm in the Middle (Fox 2000-2006), which were still on the air nearly just a decade ago (and have been circulating as repeats ever since). Following this shift towards transtexts, this chapter will look at how such practices were implemented in two contemporary programs that somewhat emulate Friends (the narratives of both HIMYM and $N G$ also revolve around groups of twenty- to thirty-something flat-sharing friends), likely in the hope of becoming the next worldwide hit. The chapter will pay due attention to their specific production contexts and how these inform their approaches to transtexts.

At first glance, much of what comes to mind when examining the official transmedia materials for HIMYM and $N G$ corresponds to and confirms some of the main arguments made in scholarship on transmedia storytelling. For example, the in-character videos and tweets by Greenfield as $N G$ 's Schmidt, the "Hey Girl" interactive music video (Fox.com 2012), and The Douche Journals book ("compiled and annotated by Schmidt"), as well as HIMYM's Barney's blog, the numerous online fake websites referenced within the show, and the books Barney is credited as having created, quite obviously serve to develop the narrative universe 
of the programs, and as advertising tools for the show. These digital and hardcopy materials help to promote the sitcoms to viewers (the more engaged of whom will be likely to seek them out) and non-viewers (who may come across them on YouTube, Twitter, etc.) alike.

Then, these HIMYM and $N G$ transtexts fall towards that end of the centripetal-centrifugal transmedia spectrum that, as Jason Mittell (2015) discusses, is less concerned with narrative expansion and driving the storytelling forward, and instead focuses on allowing the audience to spend more time with the character (predominantly Barney and Schmidt, respectively), providing additional depth without expanding or disrupting the storyworld. This characterdriven approach to transtexts furthers additive comprehension (see Jenkins 2011) by offering a sense of backstory to the characters. So, with, for example, the books containing no major information that deviates from their television shows and/or would be likely to challenge the audience's understanding of the latter, the Douche Journals book (Schmidt 2012), for instance, chronicles Schmidt's behavior from 2005 to 2010 (i.e. prior to the arrival of Jess (Zooey Deschanel) in the storyworld and thus the beginning of $N G$ ). Listing up the "infractions" (i.e. moments of unacceptable conduct) that Schmidt needs to pay a fine for, which is continued in the program via the use of the "douchebag jar", the book provides some insights into the friendship between Schmidt and Nick (Jake Johnson), helping the reader gain a vivid sense of Nick's long-standing frustration with Schmidt. Similarly with HIMYM, Barney's books (Stinson with Kuhn 2008; 2009; 2010) develop other elements from the "Bro Code" (the code of conduct to uphold between male friends, or "bros") and "The Playbook" (a guide for the "player" to seduce women) referred to throughout the show, and so provide more insight into the character's mind and principles. 
However, in-depth close analysis of the $H I M Y M$ and $N G$ transtexts affords a number of more noteworthy insights; insights that strongly suggest that transmedia scholarship stands to benefit from widening its customary genre choice (i.e. telefantasy) for its case studies and from making more use of in-depth close analysis in its engagement with transtexts. In particular, as our discussion will bear out, notions of texture, accepted imaginative realism and the reality envelope, as well as performance and the actor's input deserve to be paid more attention to within transtext-related scholarship.

\section{Expanding Inwards: Sitcom, Transtexts and Texture}

Neither the HIMYM nor the $N G$ transtexts are concerned with venturing into an immersive hyperdiegesis ${ }^{1}$ in the way that, for example, the mythology- and perpetuated hermeneuticdriven $^{2}$ stalwarts of transmedia scholarship, Heroes (NBC 2006-2010) and Lost (ABC 20042010), are. They do, however, offer audiences the opportunity to spend more time with the characters (mostly Barney and Schmidt, respectively), but also go beyond the latter (as it happens, through an inflection of the former): through their particular use of detail and depth, the HIMYM and NG transtexts expand inwards. This is importantly different to Mittell's (2015) notion of transmedia folding in on itself and furthermore also not quite captured by Henry Jenkins' references to how transmedia "may flesh out aspects of the fictional world" (Jenkins 2007). These transtexts deserve to be understood as expanding inwards because of the way in which they provide texture to the $N G$ and HIMYM storyworlds, both spatially and temporally, which has a particular significance for the sitcom genre.

Starting with $N G$, it is undoubtedly true that neither the source text nor its transtext extensions feature an expansion of an immersive hyperdiegesis nor perpetuated hermeneutic. This differs from HIMYM, which unfolds its narrative in a much-more chronologically focused fashion, 
explicitly placing each episode in a particular month and year, and which also has an overall temporal framework through the inclusion of several longstanding story-arcs. The main arc, of course, concerns the search for Ted's wife, the mother, along with other subjacent arcs focusing on different characters, such as the almost program-long slap countdown (from the second season to the very end of the final season). While the search for the mother is obviously the central mystery with an endlessly deferred resolution, the level of detail in the storytelling, the sub-stories and the precise (hence, realistic) temporal framework all act as a type of vast and detailed narrative space.

Such difference notwithstanding, both the HIMYM and the $N G$ transtexts show a noticeable amount of detail and effort that have been invested. The Douche Journals book consists of an interesting range of components, including several detailed lists, images of sushi Lego, a postcard and cinema tickets, a hand-drawn caricature of Schmidt, as well as specially produced photographs of Greenfield. These components display a notable level of depth, consistency and coherence, both internally within the book itself, the $N G$ text and sociohistorical actuality. For example, the depicted information on the cinema tickets for infraction 42 confirms Schmidt's enthusiasm for the 2006 “chick flick" The Devil Wears Prada - the screening times are judiciously chosen, mapping a long weekend of binge viewing for the film's opening weekend in the cinema - and the stated dates and days of the week also correspond to historical actuality.

A similar attention to detail is given for HIMYM, starting with the manner in which transtexts are introduced, something absent in $N G$ 's crossmedia strategy, a fact which problematizes the reductive assumption that the use of transtexts would inevitably become more sophisticated as time goes on. As Daniela Olek discusses, there are a number of ways in which audiences can 
be lead to different elements of a coordinated transtextual universe, including the use of the television channels' official programs pages as "portals into the transmedial world" (2013, 139). ${ }^{3}$ Another, less widespread and subtler, strategy to direct the audience (or at least, the more invested side of it) to other extensions consists of referring to such extensions within the episodes themselves (ibid. 139-40). As Olek points out in relation to HIMYM, "the characters often talk about websites they created or the blog Barney writers. Exactly these sites can be found by the viewers if they go online" (ibid. 140). ${ }^{4}$ As of 2015, the blog - which has not been updated since the end of the program, but remains online - features Barney's posts, as well as other sections showing pictures of Barney, the posters from the character's office, an “about me” page, and links to various websites and books (Barney Stinson Blog 2015a).

Crucially, references to a transtext can also take place through a domino effect, as would be the case when a webseries (here defined as an online extension of a television program) ends up providing a link to another extension for the viewer, such as a videogame (or vice-versa). Such is the case with HIMYM, where Barney's blog is not only diegetically embedded in the television series, but also provides links to other websites referenced in the show (Barney Stinson Blog, 2015b); the blog references no less than eleven websites, as well as a Facebook (2015) fan page supposedly made by Barney. Viewers can move between fake breast reduction doctor (Stinson Breast Reduction 2015) and lawsuit practice (Linson Breast Lawsuit 2015) pages and fake profiles featuring Barney as an eccentric millionaire (Balloon Explorers Club 2015; Big Business Journal 2015), pages mocking fellow character Ted Mosby (Josh Radnor; Ted Mosby is a Jerk 2015), presenting their joint bar idea (Puzzles, 2015), or Barney's Not a Father's Day (2015), as well as the infamous SlapCountdown.org (2015) website and Barney Stinson's video resume (2015). Retracing the entire history of the program, while bringing further information on different characters, from Barney's intricate 
web of lies in order to seduce gullible women to Ted's dream bar, the cross-referencing of these online extensions constructs a sort of transtextual and cross-narrative web and facilitates the directing of more viewers to and across the extensions.

Able to withstand a noteworthy degree of close scrutiny, the detail and consistency to be found within the $N G$ and HIMYM transtexts are reflective of the shift towards aesthetic and narrative complexity and quality that the genre of sitcom is commonly understood as having taken in the last decade or so, a shift which has sought to challenge and make a break with the notions of "unworthiness" (see Attallah 2003) that have long plagued the genre. Importantly, the level of detail, depth and consistency of the $N G$ and $H I M Y M$ transtexts links to notions concerning texture, in ways that make an intervention into existing scholarship, such as the centripetal-centrifugal spectrum outlined by Mittell (2015). For instance, these transtexts texturize the NG and HIMYM storyworlds spatially by showing details that can be hard to take in when watching the show. Barney's blog features the motivational posters from his office, which are usually a brief glimpse within the program, but here can be viewed at one's own pace, with details about the use of color and fonts becoming more observable. Similarly, infraction 151 in the Douche Journals book involves a photograph of a bottle of cleaning fluid with a used washing-up sponge by the sink in the $N G$ apartment, with the grain of, and stains on, the wood of the shelf above the sink clearly visible.

As the examples above demonstrate, the HIMYM and $N G$ transtexts contain a strong sense of texture, a concept insightfully discussed by Lucy Fife Donaldson (2014) in relation to the study of film, and which has much potential for scholarly engagement with both television and transmedia. This texture in the HIMYM and $N G$ transtexts brings out the tactile properties of their respective storyworlds, making their audiences synaesthetically aware of the 
storyworld's sensory materiality, one in which the design details of Barney's motivational posters and the grain of the wood of the kitchen shelf in the $N G$ apartment would be present and available to be inspected, and for the latter, even touched and felt. What is more, Barney's motivational posters were at one point available to order from the Barney Stinson Blog, and they and physical copies of the $N G$ douchebag jar continue to be available for purchase as tiein merchandise on Amazon (2015). Thus, these objects, as well as the books accredited to Barney and Schmidt, provide actual physical texture to those interested in examining them from up close, handling and hanging/touching them.

\section{Complementary Complexity: Texture and Temporality}

As Fife Donaldson further points out, texture, however, "is not limited to the sense of touch, but encompasses broader expressions of quality and nature" $(2014,1)$. And indeed, in addition to grounding the storyworlds in the "realness" of their spaces, the HIMYM and NG transtexts also furnish their storyworlds temporally. As mentioned, the Douche Journals book provides information about Schmidt and the storyworld during the pre-pilot years. This is complemented by the in-character videos: both released during 2011, the "Online Dating Video" and the "We Found Love" videos (Greenfield 2011a and 2011b) are explicitly placed in an earlier time period (2008 and 2002 respectively), thus adding moving image-based detail to the (internally and externally consistent) timeline constructed by the book. Something very similar occurs on HIMYM with the Robin Sparkles "Let's Go To The Mall" video (and subsequent others), aired both within the program and online on YouTube (CBS 2006), which also take place years before the beginning of the narrated stories, providing snatches of Robin's (Cobie Smulders) teenage pop career in her native Canada. 
More noteworthy for our argument, however, is that the $N G$ book and the in-character Schmidt tweets (Greenfield with Rakhe 2011) also link to actual historical dates: the book's infractions cover events taking place on specific days between 1 January 2005 and 20 September 2010, and each SchmidtTip tweeted by Greenfield in early 2012 was sent on a particular day, with Twitter temporarily displaying the precise time of its release. This finds resonance with the Slap Countdown website (2015), which, linking to the slap bet storyline that ran through eight seasons of HIMYM, counted down live the number of slaps Barney was still subject to receive from Marshall (Jason Segel).

Such temporal materiality adds specificity to a genre that has long been understood as taking place within an unspecified contemporaneity, a "timeless now" (Eaton 1978, 70). This complements and enhances the temporal complexity already found within $N G$ and (even more pronouncedly) HIMYM, which feature flashbacks to certain points in time, such as characters' childhoods and college years (and HIMYM further makes use of flash-forwards), and mark temporal occasions: episodes of HIMYM are explicitly placed in particular months and years, and, for instance, $N G$ episode "TinFinity" (2.18) celebrates the March anniversary of Nick and Schmidt living together, which is first mentioned in "Models" (2.5).

The physical and temporal textures within and of the $N G$ and HIMYM transtexts provide added specificity and dimensionality to their storyworlds; storyworlds in which experiences (such as those chronicled by the transtexts) would take place not only in specific moments within an evolving temporality uncontained by the episodes of, and flashbacks/flash-forwards within, the programs, but also in a sensory materiality where specific physical qualities and attributes, such as weight or surface roughness/smoothness, occur. Indeed, navigating through the complex webbing of the HIMYM online transtexts even echoes for the viewer / user the 
texture of the lived experience of a character within the storyworld moving between these websites. The viewer/user - the experiencer - here becomes almost "one of the gang", doing the same thing, in the same way as Barney's friends would have when shown these websites by him within the storyworld.

This highlighting of texture by the transtexts has particular meaning and importance for the genre of sitcom, long dismissed as somewhat "flat": the traditional proscenium arch model of sitcom production, with its adherence to the fourth wall principle, planimetric $\mathrm{x}$-axis blocking, ${ }^{5}$ lessened use of close-ups and deployment of noticeably artificial outdoors locations, has conventionally been understood as engendering a zero-degree style (see Caldwell 1995) devoid of depth or texture. Simultaneously, the historical use of episodic storytelling's circularity, in which the "sit" in "sitcom" remains largely unchanged, and a predisposition towards punch lines (if not catchphrases) have compounded sitcom's association with a "flatline" temporality, and this formal/structural/temporal rigidity has been understood by several critics (e.g. Swanson 1982) as linked to an inherent ideological conservatism, whereby change is shown to be impossible. Significantly for the genre, the presence of texture within the $N G$ and $H I M Y M$ transtexts shows the texture existent within the source texts and also reflects this texture back onto the source texts, thus pointing to a reciprocal relationship between television program and transtext material.

\section{Pushing the Reality Envelope by Transpiring to Accepted Imaginative Realism}

We would now like to consider what kind(s) of spectatorial engagement the $N G$ and HIMYM transtexts engender through the presence of texture within them, as well as the fact that a good number of these transtexts are in-character. Here, we would like to introduce the term accepted imaginative realism, by which we mean that the $N G$ and HIMYM transtexts offer to 
their audiences the opportunity to willingly (continue to) suspend their disbelief, agree to play along and "believe" that the transtexts are "real" (i.e. that the in-character books and tweets were written by the characters). Using the possibilities offered by transtexts, this is an imaginative game between, on the one hand, the production people ${ }^{6}-$ who make a deliberate investment of creative labor in order to deliver a more vivid, life-like and compelling storyworld - and the audience, who, becoming further engaged, plays the game by "believing" in the transtexts, in a way reminiscent of the we-know-they-know doublecodedness of the postmodern as famously formulated by Umberto Eco (1985, 67-68).

We would also like to introduce another term, namely that of the reality envelope, in order to express the situation from the production perspective, rather than the reception one, where the former has a specific agenda, namely attempting to push this (reality) envelope in order to penetrate beyond the television screen and so bring this impression of reality to the audience. In addition to the 'pushing the envelope' idiom, this term was also chosen because an envelope is a spatial object, here referencing how transtexts "hover" around their storyworlds, akin to a bubble of sorts. Also, envelopes can be delicate, bound to crumple and tear, and this notion of fragility will be useful for and emphasized by our analysis.

With the HIMYM and $N G$ transtexts, the reality envelope is supported by the presence of texture. For example, the Douche Journals book did not only use specially produced photographs of Greenfield as Schmidt, but an effort was made to make these photos appear as though they were taken at distinct moments: even though it seems likely, logically speaking, that the images for infractions 14 and 117 (which both feature a somewhat topless Schmidt by the apartment door) were taken within the same photographic session, slight changes to the set dressing across the images (with an extra jacket visible on the coat rack for 117) allows 
the audience to believe that time really did go by between the photographs. This background detail may appear incidental, but does indicate separate moments in time and reaffirm a "lived-in" quality to the space, thus providing and reinforcing enough sense of diachronicity and credibility to sustain the accepted imaginative realism.

In the case of HIMYM, it is first of all worth noting briefly in relation to the reality envelope that the numerous fake websites that Barney has supposedly made within the source text really do exist online, as though they had truly been set up by Stinson in order to keep multiplying his conquests through his ever-advanced schemes. Ironically enough, therefore, even though Barney's online profiles are fake (within the storyworld), there is simultaneously a sense of truthfulness to their existence, which makes an interesting addition to the accepted imaginative realism. Moreover, the constructed web of transtexts also furnishes the reality envelope in that Barney's blog, which is the most developed of the online HIMYM transtexts and diegetically embedded within the program on multiple occasions, allows the character of Barney to gain a new dimension, or "reality". Through his cross-webbed presence, Barney to some extent penetrates the confines of the two-dimensional television image and the television set and reaches into the virtual world. Indeed, while we do not wish to overstate this point, as the cross-webbing of the HIMYM transtexts reaches a point of exhaustion relatively quickly, it is worth noting that, nevertheless, through the possibilities of transmedia storytelling, Barney - via some kind of fifth wall - becomes a sort of multi-dimensional presence in the audience's (real) world and experience of media consumption, in which they surf the internet (clicking through hyperlinks such as those provided by the HIMYM transtexts), read websites (including blogs such as Barney's), listen to podcasts and audiobooks (Neil Patrick Harris voices the audiobooks for the Bro Code books) and purchase items online. 
We mention the purchase of items online, because Barney's blog provides advertising and direct amazon.com (and other localization) links to The Bro Code and The Playbook, as well as Bro on the Go, a shorter but updated version of the former. As Daniela Olek $(2013,140)$ rightly notes, these books, which can be bought, "transfer the fiction into the recipients' reality". Moreover, as already mentioned when discussing texture, due to their inherent physicality, such transtexts - which further include Barney's motivational posters, which were at times for sale on his website (Barney Stinson Blog 2015d), as well as the $N G$ “douchebag jar", which can be bought on amazon.com - transcend two-dimensional screen images to enter our physical reality. Resultantly, these transtexts have a physical, literal materiality and so can be felt and touched. Texture thus becomes physical, permeating from the digital world to the material one, adding this dimension to the transtextual narrative. With their real-life texture, these transtexts not only physically enter into the audience's dimension, but also, in a certain manner, allow the characters to which they are linked (Barney and Schmidt) to be further imagined as existing beyond the confines of the screen, as writing the books and as owning/holding copies of the same physical objects (books and jar) that the engaged viewers own/hold.

With the imaginative play facilitated by the HIMYM and $N G$ transtexts thus sketched out, it is worth considering the ways in which the reality envelope is necessarily temporally limited and fragile. As the creative production for HIMYM came to an end in 2014, HIMYM's reality envelope has been diminishing, with Barney's blog receiving no further updates ever since and the existing transtexts of course unable to capture any sense of an ongoing, evolving storyworld. Undoubtedly, the same will happen to the reality envelope for $N G$ once that show ceases broadcasting. ${ }^{7}$ However, the reality envelope for both has been subject to compromise 
since their very beginnings: for example, while the three Barney books are credited on Barney's blog as written by Barney Stinson (Barney Stinson Blog 2015c), the inside and outside of the books themselves do credit a second author, namely Matt Kuhn, a HIMYM staff writer, and refer to the show and its broadcasting channel. Whilst the NG Douche Journals book chooses to keep the ghostwriter invisible, its front cover highlights its connection to "the hit Fox show New Girl” (Schmidt 2012), and Schmidt (unlike Barney) does not receive an amazon author page. That the reality envelope is (inevitably) always compromised is, of course, partly linked to the need to ensure that the transtexts are sufficiently marketed to and identifiable as transtextual extensions of their source texts for the audience/consumer. All in all, while the $N G$ and $H I M Y M$ transtexts create, furnish and, as it were, push their reality envelope in interesting ways, there is a notable absence of an overall, consistent strategy in terms of each show's transtexts, which strains the accepted imaginative realism and firmly delimits and weakens the reality envelope for both.

\section{Transtexts, Performance and the Actor's Input}

One issue that has been implicitly present in our discussion so far concerns the significance of performance, and it is worthwhile and timely to now devote more sustained attention to this. As the observant reader is likely to have noticed, the HIMYM and $N G$ transtexts are not focused - as one could reasonably expect - on the perpetuated hermeneutic concerning the identity of the mother, nor indeed on any of the romantic storylines (e.g. Jess and Nick's willthey-won't-they relationship). No, the transtexts for both shows are notably focused on one character each, namely Barney Stinson and Schmidt; two characters who have much in common. They are strongly expressive about their very particular views and interests. Both are heavily invested into their appearance (to the point of narcissism), with a predilection for suits, in order to attract women and professional success. Struggling with abandonment by 
their fathers, each has overcome his previous (to him, restrictive) identity - Schmidt stopped being overweight (with Max Greenfield donning a prosthetic suit in 'Fat Schmidt' flashbacks), and Barney ceased to be a hippie - in order to seek success in a highly competitive corporate environment. Unsurprisingly, given their genre context, both frequently prefer game playing to revealing their true feelings. Both characters are, in many ways, jerks - Barney's misogynist treatment of women would call for frequent deposits to the douchebag jar Schmidt pays into for his objectionable behavior / views - and yet likeable and popular with audiences at the same time. Transgressive in that they often go beyond the conventional limits of social behavior (e.g. Barney's myriad fantastical schemes to seduce women, Schmidt's douchebag jar infractions and over-investment into his friendship with Nick), they are widely considered to be the breakout characters of their respective programs. ${ }^{8}$

If this brief summary already indicates the importance of performance and performativity for these two characters, then this is only reinforced by the fact that the actors who play them have been generally considered the noted break-out performers of their respective shows: ${ }^{9}$ Neil Patrick Harris and Max Greenfield have received much positive attention for their work in these roles, especially the presence of a certain excessiveness in their performance styles. As Gawker's Brian Moylan has rightly noted, “Barney's character has always been portrayed with a wink and a nod" (2010), with a sense of tongue-in-cheek knowingness discernable within Neil Patrick Harris' energetic, heightened performance. This is most explicitly the case when he winks directly at the camera, usually immediately following a particularly objectionable utterance by him, and in those deliberately posed, constructed shots such as the "snapshot" of Barney dressed in a suit even when waterskiing during episode "Girls Versus Suits" (5.12) - as Lauren Jade Thompson argues, Barney's character is closely linked to “excess, display, exaggeration.” $(2015,27)$ 
There is some resonance here between his performance as Barney and Greenfield's portrayal of Schmidt; the latter's performance also becomes visible as a performance. For example, "The Story of the 50" (1.10) contains two segments of alternate jokes ("alts") featuring Schmidt committing douchebag jar infractions. Here, the static camera capturing Greenfield in a medium shot and the frontal lighting creating shadows against the back wall make this look very much like a performance area, specifically, a stand-up stage. This audio-visual framing, the sequentially displayed "alts" and Greenfield's considerable (and noticeable) use of improvisation instill a performative quality here. Transgressing conventional codes of screen performance (which on the level of characterization mitigates their characters' jerklike qualities), Harris' and Greenfield's acting are clearly one of the key pleasures of their source texts, and so it is not surprising that much of the HIMYM and $N G$ transtexts is devoted to them, and that an effort has been made to produce a recognizable and consistent voice within these.

For example, the HIMYM books and blog, which are devoted to and appear as authored by Barney Stinson, were ghostwritten by the same writer, the already mentioned Matt Kuhn (who also supplied an in-character section to Harris' autobiography (Harris, 2014)). A staff writer for HIMYM, Kuhn scripts the books and blog in a way that draws on and retains a residual presence of the way of thinking, rhythms and vocal intonations that Barney employs in the program. Kuhn himself has noted that, with the writing process for source text and transtexts being very different for him, “[a]bout the only constant is Barney's voice.” (cited in Yin, 2011) This consistency is certainly born out by the fact that, for example, the Slap Judgment page entry on Barney's blog (Barney Stinson Blog, 2015e) - which sees Barney making a "slappeal" in the form of a complaint against Slap Bet Commissioner Lily Aldrin 
(Alyson Hannigan) in response to the events in episode "Slapsgiving 3: Slappointment in Slapmarra" (9.14) - very much reads like a page from a HIMYM script: one can easily picture the scene, in which Barney quickly shifts, as his character often does, from a formal idiom ("time to levy an appropriate punitive action") to a colloquial register ("that leopard print thong I know she's got stashed away”).

The significance of voice/performance here needs to be understood within the production context of HIMYM, in which, as is common with long-running shows, the scriptwriters (including Kuhn) came to write for the specific qualities and strengths of the particular performers cast for the main roles. As HIMYM co-showrunner Craig Thomas has acknowledged, the autobiographical roots of HIMYM's key characters notwithstanding, "the characters [...] become their own people, a collaborative construct between actors and writers." (cited in Landau 2014, 282) In the case of Harris, this includes the fact that he is a skilled illusionist - another way in which this actor is marked by performativity - and can handle the rapid, high-octane delivery of long lines of dialogue, as well as manage balancing between misogynist arrogance and vulnerable likeability; all of which undoubtedly aided the characterization of Barney, both within the source text and subsequent transtexts. Harris recalls that he "began taking ownership" $(2014,143)$ of Barney, noting that, in addition to being closely involved in costuming choices, he also began to subtly direct attention towards Barney's evolving feelings for Robin "to see what the writers would do with that." (ibid.) So, the voice of Barney needs to be understood as a composite of script writing and Harris' input, and this carries through from the source text to the transtexts, especially because the latter employed the same staff writer, who evidently has a positive working relationship with the actor in question. 
With $N G$ 's transtexts, the voice of Schmidt also comes through, if anything more pronouncedly so. Indeed, reviews of the Douche Journals have insisted that "the reader hears [the book's infractions] in Schmidt's inimitable intonation" (Thomas 2012), and we would extend this to the tweets as well. Indeed, the presence of Schmidt's voice is so strong across the $N G$ episodes, infractions from the Douche Journals book and the tweeted SchmidtTips, that it would be difficult to distinguish between extracts of these sans contextualizing information. Consider, for example, the congruence between "Has anyone seen my croquet cleats?", "Ranch dressing is overalls and a straw hat, NOT something to be drizzled on a bed of arugula and endives", and "In the oatmeal game, it's steel-cut or $\underline{B E}$ cut."

That the voice comes through rather strongly links to the particular emphasis given within $N G$ 's production context on actorly input, with much use of improvisation (whereby the actors are encouraged to spontaneously try out different ideas) and a large number of alternate jokes ("alts"), which are "thrown at the actors during filming" (Sepinwall 2013) and sometimes sequentially included within episodes. Clearly, a high degree of collaboration informs the program, as co-showrunner Elizabeth Meriwether has emphasized: “There's so much of the show that's just improv and in the moment, and what they [the actors] bring to the scene. [...] We throw stuff at them and just see what they do with it, and I think you really can see it." (cited in Radish 2012) Not part of the crop of alumni of improv companies such as The Second City who are currently finding much success in film and television, the $N G$ core cast evidently enjoys the opportunity to engage in unscripted creative collaboration to develop scenes. This particular input by the actors is enabled through the valuing of the actors' contribution to the creative process and attendant flexible approach to the script text, a high shooting ratio and through cross-covering many scenes - as Jake Johnson explains, this means that "there's a shooting camera on each person at the same time" (cited in Paskin 2012), 
which of course interestingly complicates $N G$ 's single camera status - so that the actors can play off each other.

So, the $N G$ production methods are hinged around a closely collaborative approach between cast and crew, which goes beyond the more established ways in which actors get to have input on the characters they play in long-running shows. Interestingly, this collaborative approach does not begin and end with the program: the SchmidtTips on Twitter (Greenfield with Rakhe 2011) were jointly devised by one of the show's writers and Max Greenfield, resulting in tweets such as this one from 4 March 2012:

\#SchmidtTip \#24 When I'm having a bad day I throw on my smartest flannel and assemble a piece of Ikea furniture with my bare hands. \#grit

As Greenfield has elaborated, this collaboration on transtexts emerged quite organically during the show's production process:

Me and one of the writers, Luvh Rakhe, have been goofing around and we're always like, "We gotta make Web content, we gotta make Web content!" And our writers work so hard and are literally there 16 to 18 hours, and the last thing they're thinking about is Web content. Schmidt Tips was supposed to be like Web content but it just felt more like a Twitter thing, so we started to do it and they're so much fun. (cited in Bricker, 2011)

That Greenfield has had more (direct) input and investment into the creative process of shaping the voice of his character in $N G$, both within the source text and transtexts, ${ }^{10}$ than for example Harris had with his character in HIMYM needs to be recognized as a crucial factor why the voice of Schmidt is particularly distinct and discernible in the transtexts. This phenomenon of a residual presence of performance of sorts - more distinct within $N G$ 
transtexts but also present within HIMYM transtexts - reflects the importance of performance and the work of actors to the meaning and pleasures of the sitcom source texts and transtexts at the level of production and consumption, including for transtexts showcasing the written word. Transtexts are in certain ways marked by a residual sense of performance and inherent performativity: those transtexts that are supposedly written/produced by a character are located within a performative frame because audiences know they are supposed to playfully engage with them as though they stem from the fictional character. Those transtexts that do not directly feature the performer(s) from the source text are permeated with performativity in that (an actor's) performance and the voice of a character here need to be performed and reproduced via other means, such as terminology, syntax, typographical layout and imagination, by both the production team and audience alike. ${ }^{11}$

\section{The Actor's Input and Transmedia Authorship}

To remain focused on $N G$ and Greenfield's input into Schmidt for a moment longer, this collaborative approach certainly raises issues concerning copyright, as well as authorship and canonicity - topics further discussed in Jennifer Henderson's and Benjamin Derhy Kurtz's chapters, respectively - across text and transtexts. Greenfield's input has been even more decisive for a different type of transtext, namely the in-character videos: not only is his improvisation work crucial to, for example, the "Work Out Video" (Greenfield 2012), but the very first in-character video to appear - the "We Found Love" video (Greenfield 2011a) in which he lip-synchs and dances to a Rihanna song - was made and released by Greenfield himself on his own initiative whilst wearing the prosthetic "Fat Schmidt" suit. The video was quickly taken down from YouTube by the studio, because Greenfield's creative act did not take into consideration copyright issues, as Greenfield details whilst describing his initiative behind the dating video (Greenfield 2011b): 
I had originally made this video in the fat suit and I was singing a Rihanna song. It got pulled down, which was a real bummer, but it would have gotten pulled down at some point anyway. We [sic] were like, "Listen, Max, there were so many things wrong with the video that you made and you've got to consult us." Because Extra had the rights to reveal Fat Schmidt, and then we didn't have the rights to the song, [...]. [...] I went to them and I was like, "How much would it be for the Natasha Bedingfield song?" It took us a few weeks, but we finally got the rights, and then once we got the rights we went and made the [dating] video. (cited in Bricker 2011)

Evidently, Greenfield and his character Schmidt have been pivotal to the $N G$ transtexts, even constituting effectively free labor at one point. With the $N G$ production methods offering notable creative input and investment for actors, it is not difficult to understand this input and investment as giving an actor inclination to move beyond the usual boundaries of on-screen performance and instigate further creative acts. Clearly, issues of agency, control, authority, legitimacy, the canon and copyright become pronounced here. Greenfield's unauthorized work offers an interesting inflection to debates about the ways in which transtexts arguably foster collaborative, decentralized models of authorship: while transmedia storytelling has been understood as possessing such a democratizing potential, Jenkins has observed that "the most successful transmedia franchises have emerged when a single creator or creative unit maintains control" $(2006,106)$. Suzanne Scott has further noted the ways in which transmedia storytelling systems and "authorized" or "official" ancillary content can reinforce "the textual authority of a limited few, even as the text itself expands" (2010, 31). Greenfield's work for the "We Found Love" video is no radical act of defiance, to be sure, ${ }^{12}$ but given his status as one of the key performers and the break-out star of the first season, it nevertheless raises some important questions: whilst not authorized, is his first video official, or (likely to be) taken as 
such by fans? Is it canon, or (likely to be) received as such? At what point would the invocation of such terms seem (in)appropriate or (un)justified? And where does (and/or should) the creative copyright for these transtexts reside? One thing is for sure, namely that more consideration of the position and status of the actor within the cultural hierarchies of transmedia storytelling will offer a fascinating enrichment to scholarly discourse, so much of which has focused on producers / writers and audiences.

\section{Conclusion}

Drawing to a close, we would like to note that our chapter is, to the best of our knowledge, the first scholarly publication to provide an in-depth examination of transtexts and sitcom. More research on transmedia and sitcom is well deserved, seeing as it is bound to uncover further fascinating media practices, which will need to be understood within their particular production contexts. With our chosen case studies, HIMYM and $N G$, transtexts reinforce the importance of moving away from long-standing tendencies to understand (especially multicamera) sitcom as linked to flatness and devoid of complexity. ${ }^{13}$ These extensions demonstrate the need (and opportunity) to think carefully about the ways in which viewers are invited to engage with transtexts, and that this imaginative engagement would be more successfully facilitated by a more cohesive strategy. Finally, these transtexts show the need for nuanced comprehension of the importance of performance as well as the status, creative input and work of actors for both source texts and transtexts. As our chapter has demonstrated, in-depth close analysis of selected case studies adds useful specificity to debates about transmedia, letting pertinent concepts and ideas - here, texture, accepted imaginative realism and the reality envelope, as well as performance and the actor's input emerge. Individually and collectively, these concepts and ideas have much scope for enriching debates on transtexts, and we invite others to engage with these opportunities and 
test out these concepts and ideas against other case studies, be they from within or beyond the genre of sitcom.

We dedicate this chapter to the memory of Umberto Eco, who, we know, knew many things.

\section{References}

Amazon. 2015. "New Girl Douchebag Jar.” Amazon.com. Accessed August 24, 2015. http://www.amazon.com.Shop-Fox-FOX-NG-051812-001-Girl-Douchebag/dp/B0086EW6JK

Attallah, Paul. 2003. “The Unworthy Discourse: Situation Comedy in Television.” In Critiquing the Sitcom: A Reader, edited by Joanne Morreale. 91-115. Syracuse, N. Y.: Syracuse University Press.

Balloon Explorers Club. 2015. BalloonExplorersClub.com. Accessed July 23, 2015. http://balloonexplorersclub.com.

Barney Stinson Blog. 2015a. BarneyStinsonBlog.com. Accessed July 17, 2015. http://www.barneystinsonblog.com.

Barney Stinson Blog. 2015b. "Links." BarneyStinsonBlog.com. Accessed July 17, 2015. http://www.barneystinsonblog.com.links/

Barney Stinson Blog. 2015c. "My Books.” BarneyStinsonBlog.com. Accessed July 17, 2015. http://www.barneystinsonblog.com.my-books/

Barney Stinson Blog. 2015d. "Motivational Posters." BarneyStinsonBlog.com. Accessed July 17, 2015. http://www.barneystinsonblog.com/motivational-posters/

Barney Stinson Blog. 2015e. "Slap Judgment." BarneyStinsonBlog.com. Accessed December 26, 2015. http://www.barneystinsonblog.com/slap-judgment/

Barney Stinson's Video Resume. 2015. BarneysVideoResume.com. Accessed July 23, 2015. http://barneysvideoresume.com. 
Bazilian, Emma. 2014. "Max Greenfield Is Glad Fox Forced Him to Use Twitter”, Adweek, July 2. Accessed August 18, 2015. http://www.adweek.com.news/television/maxgreenfield-glad-fox-forced-him-use-twitter-158626

Big Business Journal. 2015. BigBusinessJournal.com. Accessed July 23, 2015. http://bigbusinessjournal.com.

Bricker, Tierney. 2011. “2011 Breakout TV Stars: New Girl’s Max Greenfield Talks About Playing the Glorious Shirtless Creature That Is Schmidt", Eonline, December 31. Accessed August 18, 2015. http://uk.eonline.com.news/283395/2011-breakout-tv-stars-newgirl-s-max-greenfield-talks-about-playing-the-glorious-shirtless-creature-that-is-schmidt Butler, Jeremy G. 2010. Television Style. New York and London: Routledge.

Caldwell, John Thornton. 1995. Televisuality: Style, Crisis, and Authority in American Television. New Brunswick, N. J.: Rutgers University Press.

CBS. 2006. "Robin Sparkles "Let's Go to the Mall” (full version)". Youtube.com, 22 November. Accessed July 24, 2015. https://www.youtube.com.watch?v=9mJAsgIIfNM Eaton, Mick. 1978. “Television Situation Comedy” Screen 19: 4, 61-89.

Eco, Umberto. 1985. "Postmodernism, Irony, the Enjoyable" in Reflections on the "Name of the Rose", translated by William Weaver, 65-72. London: Secker \& Warburg.

Facebook. 2015. "Barney Stinson Blog." Facebook.com. Accessed July 23, 2015. https://www.facebook.com.The.Barney.Stinson.Blog

Fife Donaldson, Lucy. 2014. Texture in Film. London: Palgrave Macmillan.

Fox.com. 2012. "Hey Girl” interactive music video, no longer available online.

Garron, Barry. 2006. “Blog Heaven.” Emmy Magazine, 198-9, July 19.

Greenfield, Max with Rakhe, Luvh. 2011. "SchmidtTips", Twitter.com. Accessed August 18, 2015. https://twitter.com.iamgreenfield 
Greenfield, Max. 2011a. "Schmidt Online Dating Video 2008”. Accessed December 12, 2015. https://www.youtube.com/watch?v=Zkf5SSdfQYA

Greenfield, Max. 2011b. “We Found Love' feat. SCHMIDT (visual remix 2002)”. Accessed December 12, 2015. https://www.youtube.com/watch?v=hddsKBHKqm8

Greenfield, Max. 2012. "Schmidt's Work Out Video”. Accessed December 12, 2015. https://www.youtube.com/watch?v=n7GklAJOoHo

Harris, Neil Patrick. 2014. Choose Your Own Autobiography. New York: Three Rivers Press.

Hills, Matt. 2002. Fan Cultures. London and New York: Routledge.

Jenkins, Henry. 2006. Convergence Culture: Where Old and New Media Collide. New York: New York University Press.

Jenkins, Henry. 2007. "Transmedia Storytelling 101”, Confessions of an Aca-Fan: The Official Weblog of Henry Jenkins, March 22. Accessed August 18, 2015. http://henryjenkins.org/2007/03/transmedia_storytelling_101.html

Jenkins, Henry. 2011. “Transmedia 202: Further Reflections”, Confessions of an AcaFan: The Official Weblog of Henry Jenkins, August 1. Accessed August 18, 2015. http://henryjenkins.org/2011/08/defining_transmedia_further_re.html

Jenkins, Henry, Ford, Sam and Green Joshua, eds. 2013. Spreadable Media: Creating Value and Meaning in a Networked World. New York: NYU Press.

Klastrup, Lisbeth, and Susana Tosca. 2004. "Transmedial Worlds-Rethinking Cyberworld Design." Proceedings of the 2004 International Conference on Cyberworlds, 409-16. Accessed July 14, 2015. doi: 10.1109/CW.2004.67.

Landau, Neil. 2014. The TV Showrunner's Roadmap: 21 Navigational Tips for Screenwriters to Create and Sustain a Hit TV Series. Burlington, MA and Abingdon: Focal Press. 
Linson Breast Lawsuit. 2015. LinsonBreastLawsuit.com. Accessed July 23, 2015. http://www.linsonbreastlawsuit.com.

Mills, Brett. 2009. The Sitcom. Edinburgh: Edinburgh University Press.

Mittell, Jason. 2015. Complex TV: The Poetics of Contemporary Television Storytelling. New York: New York University Press.

Moylan, Brian. 2010. 'Neil Patrick Harris: Television's First 'Straight' Character”, Gawker, January 12. Accessed August 18, 2015. http://gawker.com/5446329/neil-patrickharris-televisions-first-straight-character

Newman, Michael Z. and Levine, Elana. 2012. Legitimating Television: Media Convergence and Cultural Status. New York: Routledge.

Not a Father's Day. 2015. NotAFathersDay.com. Accessed July 23, 2015. http://notafathersday.com.

Olek, Daniela. 2013. "TV for the Post-TV Generation? How Transmedia Television Series Yearn for Another Type of Audience.” In (Dis)Orienting Media and Narrative Mazes, edited by Julia Eckel, Bernd Leiendecker, Daniela Olek, Christine Piepiorka, 129-44. Bielefeld: Transcript.

Paskin, Willa. 2012. “New Girl's” Jake Johnson is a big tease”, Salon, October 14. Accessed August 18 , 2015. http://www.salon.com.2012/10/14/new_girls_jake_johnson_is_a_big_tease/

Puzzles. 2015. PuzzlesTheBar.com. Accessed July 23, 2015. http://www.puzzlesthebar.com.

Radish, Christina. 2012. "Zooey Deschanel and Liz Meriwether NEW GIRL Interview", Collider, January 15. Accessed August 18, 2015. http://collider.com.zooeydeschanel-liz-meriwether-new-girl-interview/ 
Richards, Denzell. (2010) "Cult TV and New Media” In The Cult TV Book, From Star Trek to Dexter, New Approaches to TV Outside the Box, edited by Stacey Abbott, 179-88. New York: Soft Skull.

Schmidt. 2012. The Douche Journals - Volume One: The Definitive Account of one Man's Genius. New York: itbooks.

Scott, Suzanne. 2010. “The Trouble with Transmediation: Fandom's Negotiation of Transmedia Storytelling Systems" Spectator vol.30 no.1, 30-34.

Sepinwall, Alan. 2013. "How a 'New Girl' script gets made: From outline to final cut on 'TinFinity'”, What's Alan Watching?: Inside Television with Alan Sepinwall, February 27. Accessed August 18, 2015. http://m.staging.hitfix.com.whats-alan-watching/how-a-new-girlscript-gets-made-from-outline-to-final-cut-on-tinfinity/single-page

SlapCountdown.org. 2015. SlapCountdown.org. Accessed July 23, 2015. http://slapcountdown.org

Stinson, Barney with Matt Kuhn. 2008. The Bro Code. New York: Fireside.

Stinson, Barney with Matt Kuhn. 2009. Bro On The Go. New York: Fireside.

Stinson, Barney with Matt Kuhn. 2010. The Playbook: Suit Up. Score Chicks. Be Awesome. New York: Fireside.

Stinson Breast Reduction. 2015. StinsonBreastReduction.com. Accessed July 23, 2015. http://www.stinsonbreastreduction.com.

Swanson, Gillian. 1982. "Law and Disorder." In Television Sitcom, edited by Jim Cook. 32-42. London: BFI.

Ted Mosby is a Jerk. 2015. TedMosbyIsAJerk.com. Accessed July 23, 2015. http://tedmosbyisajerk.com.

Thomas, June. 2012. “The Douche Journals", Slate, October 9. Accessed August 18, 2015. 
http://www.slate.com.blogs/browbeat/2012/10/09/the_douche_journals_reviewed_schmidt_fr om_new_girl_has_a_book_should_you_read_it_html

Thompson, Lauren Jade. 2015. "Nothing Suits Me Like a Suit: Performing Masculinity in How I Met Your Mother" Critical Studies in Television vol.10 no.2, 21-36.

Thornton, Karl. 2015. "SlapCountdown.com | TheSlapbetCountdown.com - How I Met Your Mother", FictionURL.com: Exploring Television's Internet, November 12. Accessed December 12, 2015. http://www.fictionurl.com/slapcountdowncom/

Vermeulen, Timotheus and Whitfield, James. 2013. "Arrested developments: Towards an aesthetic of the contemporary US sitcom." In Television Aesthetics and Style, edited by Jason Jacobs and Steven Peacock. 103-111. London and New York: Bloomsbury.

Yin, Maryann. 2011. "How I Met Your Mother Writer Matt Kuhn On His New Book", GalleyCat, January 4. Accessed August 18, 2015. http://www.adweek.com/galleycat/how-imet-your-mother-writer-matt-kuhn-on-his-new-book/21341.

\footnotetext{
${ }^{1}$ Matt Hills $(2002,137)$ defines hyperdiegesis as "the creation of a vast and detailed narrative space, only a fraction of which is ever directly seen or encountered within the text, but which nonetheless appears to operate according to principles of internal logic and extension."

${ }^{2}$ Hills (2002) defines perpetuated hermeneutic as a central mystery whose resolution is endlessly deferred.

${ }^{3}$ The author here makes use of the (rarer) expression used in Lisbeth Klastrup and Susana Tosca's (2004) seminal work, "transmedial world" (as does Denzell Richards in this book). Jenkins proposes another reading of the concept, however, by arguing in the last chapter of this collection that "transmedia" is, first and foremost, an adjective; hence the lack of necessity for another one.

${ }^{4}$ It is worth noting that there has been, however, a development, from the initial stages when Barney's blog was but a section of the CBS website (Garron 2006, 198), to that referred to by Olek (2013), which describes a freestanding, dedicated blog with its own URL.

${ }^{5}$ As Jeremy Butler (2010) explains, this approach to staging involves arranging performers along a single plane across the width of the screen.

${ }^{6}$ See Benjamin Derhy Kurtz's chapter on authority figures.

${ }^{7}$ Not that we wish to argue that an absence of updates to a transtext necessarily inevitably equates to a diminished reality envelope: the Slap Countdown website (2015) ran down to zero and has remained defunct ever since, which makes sense within the storyworld, as once the final slap was given, the countdown became purposeless. For details on this transtext's complex history and shift of domain registration, see Thornton (2015). ${ }^{8}$ There is a discussion to be had here concerning genre and contemporary masculinity, but this falls outside the scope of our chapter; see Thompson (2015).

${ }^{9}$ Harris in HIMYM is further marked by a sense of performativity in that he publicly came out in 2006, thus being an openly gay actor playing an excessive womanizer (see Thompson 2015).

${ }^{10}$ It seems likely that Greenfield's involvement in the Douche Journals book was not limited to the photographs.

${ }^{11}$ Many of the $N G$ and $H I M Y M$ transtexts are informed by performativity in that they feature actors and characters performing on several layers: for example, Harris' Barney Stinson poses as attorney Arnie Linson on
} 
the Linson Breast Lawsuit webpage, and in the "Online Dating Video" Greenfield plays Schmidt, who is clearly performing (often via self-aggrandizement) to the camera as well as playing several characters simultaneously.

${ }^{12}$ Indeed, like many of his peers, Greenfield joined Twitter because of contractual obligations (see Bazilian 2014).

${ }^{13}$ See Newman and Levine (2012) for a discussion of the evaluative discourses that inform such tendencies. 